\title{
"É muito duro esse trabalho": interação e conflito em um serviço de atendimento básico em saúde
}

\author{
Marcos Júnior Santos de Alvarenga*
}

\begin{abstract}
Resumo: A proposta do presente artigo é de entender a relação que funcionários da saúde estabelecem com seus pacientes no cotidiano de trabalho em um Centro de Saúde do Distrito Federal, à luz dos limites e possibilidades das teorias desenvolvidas por Alfred Schutz e Georg Simmel. A pesquisa esteve vinculada a um Projeto de Extensão onde foram realizadas 29 entrevistas individuais com os funcionários do Centro, servindo assim para mapear o campo e circunscrever a problemática. Ao vincular as entrevistas à teoria socioantropológica presente nos escritos de Schutz e Simmel, busco apresentar profícuas ferramentas analíticas para pensarmos questões relacionadas às representações e às relações que são vivenciadas pelos trabalhadores em seu cotidiano de trabalho. Pretendo abordar um dos pontos que me chamaram mais a atenção durante a análise das entrevistas: os conflitos que se estabelecem na relação funcionário/paciente. Serão usados os limites das ideias de conflito e de estrutura de grupo desenvolvidas por Simmel, e a ideia de interação entre grupos utilizada nos trabalhos de Schutz. A partir daí, procuro entender as percepções que os funcionários do Centro teceram acerca de seus pacientes e de sua interação com eles, e descrever a construção da figura do paciente que chega "armado" nos serviços de saúde. Ao final do texto, faço uma síntese do que foi o trabalho até então e aponto os limites da pesquisa, bem como seus possíveis desdobramentos etnográficos.
\end{abstract}

Palavras-chave: conflito, interação, atendimento ao paciente.

\section{Introdução}

A elaboração deste artigo partiu de uma Pesquisa de Extensão que tem por título "É muito duro esse trabalho": Investindo nos funcionários da Secretaria de Estado de Saúde, realizada durante o ano de $2011^{1}$. 0 campo para a pesquisa foi realizado junto à equipe de trabalhadores de um Centro de Saúde (CS) localizado em Ceilândia, região administrativa do Distrito Federal. A fim de preservar a identidade e o sigilo da equipe de saúde, o número que identifica o CS foi omitido, bem como o cargo e a função dos funcionários entrevistados.

Um dos principais problemas que foram relatados pelos funcionários entrevistados durante a pesquisa foi a relação criada no atendimento aos usuários do sistema. Os pacientes que acorrem aos serviços de saúde são caracterizados pelos funcionários como pessoas que já chegam "armadas" à unidade de saúde e estão potencialmente

\footnotetext{
* Graduando em Ciências Sociais - UnB.

${ }^{1}$ A realização do Projeto de Extensão contou com a coordenação de uma das professoras do Departamento de Antropologia e com a participação de cinco graduandos do mesmo departamento.
} 
prontas para agredir - verbal ou fisicamente - o profissional de saúde no exercício de suas atribuições. Não será de todo coincidência, portanto, o fato de encontrarmos em algumas unidades de saúde pública da capital cartazes pregados nas portas dos consultórios e nos corredores lembrando aos usuários e transeuntes o art. 331 do Código Penal Brasileiro, que estipula detenção de 6 (seis) meses a 2 (dois) anos, ou multa, em casos de desacato ao funcionário público no exercício da função ou em razão dela.

A caracterização do paciente como potencial provocador de desacatos e desentendimentos, bem como sua estigmatização, trata-se de tema que tem sido abordado por diversos trabalhos sociológicos e antropológicos no Brasil. Principalmente em contextos hospitalares, como o trabalho de Deslandes (2002), que coloca em diálogo o debate teórico mais amplo sobre violência e as atividades desenvolvidas no setor de emergência de um hospital público do Rio de Janeiro, trazendo a violência nos serviços emergenciais de saúde em dois níveis: como demanda de trabalho e na relação com o paciente. Na esfera da relação com o paciente, a autora traz para exemplificar essa dimensão o que a equipe de emergência do hospital chama de 'esquenta plantão', que são os momentos de maior tensão e agressividades vivenciadas no setor de emergência. Seja porque o paciente esperou muitas horas para ser atendido, seja porque o familiar quer que seu parente seja atendido prontamente, culminando em algumas vezes até em agressões físicas envolvendo profissionais e pacientes.

Outros trabalhos que se inserem no campo da saúde do trabalhador demonstram os tensionamentos vivenciados por profissionais no encontro diário com os pacientes no âmbito hospitalar. Como o trabalho de Bianchessi e Tittoni (2009), que demonstra que as demandas trazidas pelos pacientes frequentemente suscitam nos profissionais sentimentos de impotência - quando são demandas não resolvidas, apesar de considerarem as limitações estruturais e humanas, tensões e desgastes que levam à ocorrência de adoecimentos e afastamentos do trabalho. Somado a esta interação, há também os conflitos que advêm da relação entre a equipe de profissionais e a estrutura extremamente hierarquizada de trabalho, em que há constantemente a pressão e a responsabilidade por parte dos profissionais para não cometerem erros. Deslandes (2002) também aponta essa desigualdade hierárquica, afirmando que o processo de trabalho na saúde é desigualmente distribuído, sendo a figura do médico a detentora do saber/poder hegemônico. Porém, a autora não perde de vista o fato de que este processo de trabalho desigual admite espaços para negociações e barganhas entre seus diferentes atores. 
É justamente desse contexto conflituoso e de adoecimento que surgiu a demanda para a realização da pesquisa de extensão que serviu de norte para a produção deste artigo. Cabe lembrar aqui que existem importantes diferenças entre as experiências descritas nas pesquisas que trouxe como referência, sediadas em hospitais de média e alta complexidade, e a realidade da pesquisa desenvolvida no Centro de Saúde de Ceilândia, serviço de atenção básica, onde se deve levar em conta as diferenças entre dimensão, estruturação e as especificidades de cada serviço estudado.

A demanda à qual me referia surge de um convite da própria diretoria do Centro de Saúde, que afirmava haver uma crescente ocorrência de funcionários desmotivados que enfrentavam problemas de conflitos interpessoais, preocupações pré-aposentadoria, sofrimento psíquico e mental, desânimo para o trabalho etc. Nesse sentido, o projeto de extensão foi estruturado com o intuito de oferecer aos trabalhadores do CS informações e reflexões a partir da perspectiva teórico-metodológica da Antropologia e pensar algumas possíveis ideias e alternativas para os problemas e conflitos enfrentados no cotidiano de trabalho, reafirmando, assim, a importância das abordagens compreensivas nos estudos sobre a relação trabalho-saúde. 0 potencial interpretativo, que lançam mão as Ciências Sociais, como nos lembram Minayo-Gomez e Thedim-Costa (2003), nos ajudam a compreender não só a práxis social dos trabalhadores, mas também o trabalho enquanto categoria social, enquanto resultado de um enredado de relações políticas, econômicas, tecnológicas e sociais que se dispõem de forma conflituosa e interdependente.

A partir dos dados e experiências encontradas em campo estabelece-se a proposta deste artigo, que tenta levar adiante os esforços de aproximação e diálogo entre a comunidade e a academia. E tem o intuito de entender as experiências relatadas em um serviço de saúde básico a partir da perspectiva fenomenológica de pensadores como Schutz e Simmel, em que as interações da vida cotidiana assumem primorosas inspirações de análise: seja no estudo das formas sociais, em Simmel, seja no estudo das intersubjetividades, em Schutz.

Este artigo está divido em dois eixos de análise sequenciais: interação e conflito. No primeiro eixo, trago a dimensão da interação cotidiana, tentando demonstrar, como a concepção de interação entre grupos de Schutz (1979) pode ser aproveitada no que tange a análise da relação entre equipe profissional e paciente, sempre em consonância com a perspectiva dos primeiros. Já no segundo eixo, trago as contribuições da teoria de Simmel (1983) bem como os seus limites para análise do material 
empírico, lançando mão da noção simmeliana de conflito e seu papel na manutenção dos grupos. Em relação à ideia de conflito, demonstro como ela é caracterizada pelo autor e como, em dadas circunstâncias do cotidiano de trabalho dos funcionários do CS, ela não se aplica em seus aspectos positivos, aqueles que mantém a unidade do grupo. Ao final desses dois eixos, retomo em forma de síntese o que foi discutido até então e aponto os limites da pesquisa empírica junto à equipe do CS de Ceilândia, além dos possíveis novos desdobramentos da pesquisa etnográfica.

\section{Aspectos metodológicos: situando o leitor}

A estrutura embrionária do Projeto de Extensão que originou este artigo foi apresentada em reunião à equipe de profissionais do CS para perceber se os objetivos, ações estratégicas e metodológicas faziam algum sentido e se eram, de alguma forma, interessantes para a equipe. De forma geral, o projeto de extensão esteve sustentado por dois eixos sequenciais: (i) etapa de pesquisa e levantamento de dados, em que foram realizadas entrevistas individuais junto aos funcionários e (ii) etapa de sugestões e realização de atividades. A ideia dessa segunda etapa foi de apresentar à equipe de funcionários uma primeira análise dos dados levantados no primeiro eixo da pesquisa e, a partir daí, sugerir algumas atividades específicas a fim de servirem como alternativa para atenuar as consequências negativas da rotina de trabalho.

Na primeira parte, que corresponde à etapa de pesquisa e levantamento de dados, foram realizadas 29 entrevistas individuais com os profissionais do CS, mediante o interesse e a disponibilidade em participar, onde se tentou contemplar funcionários de todos os setores do CS, para garantir o mínimo de representatividade. Porém, somente alguns trechos das entrevistas entraram na análise que aqui se desenvolve.

Um Termo de Consentimento Livre e Esclarecido (TCLE) foi apresentado e assinado pelas duas partes (pesquisador e entrevistado), conforme preconiza a Resolução 196/1996 do Conselho Nacional de Ética em Pesquisa (CONEP/MS). O projeto foi submetido e aprovado pelo Comitê de Ética em Pesquisa do Instituto de Humanas (CEP/IH) e o Decanato de Extensão, pelo Sistema de Informação e Gestão de Projetos (SIGPROJ/MEC) ${ }^{2}$.

Foi utilizado um roteiro de perguntas semi-estruturado, elaborado previamente com base na literatura específica e relacionada com o tema do projeto. 0 roteiro con-

${ }^{2}$ SIGProj N: 88277.368.23464.0305201. 
tou com perguntas divididas nos seguintes blocos de conteúdo: panorama individual, panorama de trabalho no Centro de Saúde e perguntas específicas.

Para a segunda etapa do projeto, foi prevista a apresentação da análise dos dados levantados e, a partir daí, a sugestão de algumas atividades específicas como alternativa para atenuar as consequências negativas da rotina profissional. As entrevistas realizadas foram analisadas e comentadas pela equipe de pesquisadores, dando suporte para a elaboração do relatório final apresentado à equipe de profissionais. Juntamente com o relatório, foram apresentadas ideias de atividades que poderiam ser realizadas pela equipe de profissionais, como atividades lúdicas, confecção de cartazes e exposição de fotos. Apesar dessas ideias terem sido bem recebidas e apoiadas, não puderam ser realizadas , por motivos de organização interna do próprio CS.

Seguindo a proposta deste artigo, pretendo abordar nas páginas seguintes os pontos que me prenderam mais a atenção, devido a sua recorrência, durante a análise das entrevistas: os conflitos que se estabeleceram na relação funcionário/paciente em um serviço de atendimento básico de saúde.

\section{Interação}

Ainda que os funcionários entendam o papel da saúde pública como um atendimento que deva ser humanizado ${ }^{3}$ e de qualidade, em que o paciente é tido como prioridade e foco das atenções, no decorrer das entrevistas foi possível perceber que a relação estabelecida com os pacientes é uma das fontes de conflitos e atritos mais mencionadas. $\mathrm{O}$ contato imediato com o paciente no cotidiano de trabalho se mostrou como uma atividade cansativa - para não dizer estressante - e motivo de constantes irritações. Ao reler cuidadosamente as entrevistas, foi possível detectar que, em grande parte delas, o estresse dos pacientes é apresentado como condicionador e/ou causa do estresse sofrido pelos funcionários do referido Centro de Saúde. Talvez por esse motivo, o lidar diretamente com o público que procura atendimento seja menos valorizado sob a ótica de quem está prestando os serviços.

$\mathrm{Na}$ fala de alguns entrevistados, notou-se a presença de duas categorias que frequentemente perpassavam as histórias e explicações oferecidas durante as entrevistas, a saber: a categoria "lá fora" e a categoria "aqui dentro". Como o escopo desta

\footnotetext{
${ }^{3}$ Ainda que a questão da humanização em saúde, que apresenta por principio básico a indissociabilidade entre atenção e gestão, seja de grande importância, não será abordada de forma direta neste artigo. Para maiores informações, consultar a Política Nacional de Humanização criada em 2003, publicação do Ministério da Saúde.
} 
pesquisa esteve centrado apenas no ponto de vista dos funcionários, a categoria "lá fora" faz referencia às dependências do Centro de Saúde que são de acesso liberado aos pacientes e ao público em geral. Já a categoria "aqui dentro" faria referências às dependências burocrático-administrativas do Centro, que em teoria seriam de acesso exclusivo aos funcionários.

A partir disto pode-se dizer, mais especificamente, que é "lá fora" que se tem que conviver ou "aguentar" os pacientes. Funcionários da farmácia, da coleta de exames, das clínicas médicas, do arquivo e marcação de consultas, por exemplo, seriam os que dividiriam seu cotidiano com os pacientes, são os que estariam "lá fora" para lidar com o público. Como nos relatou uma funcionária,

Lá fora, a gente lida com o público. A gente tem que ouvir o tempo todo os problemas das pessoas. Eles desacatam funcionários, descontam muita coisa na gente. É difícil. Eu entendo que as pessoas querem uma coisa e não conseguem e, com isso, ficam chateadas. Eu queria poder ajudar mais, mas não tinha o que fazer ali. Muita reclamação, muita briga. A gente vai cansando disso. Aí, na farmácia, um amigo me indicou para o RH [Recursos Humanos] (Mulher, 47 anos, trabalha no $\mathrm{RH})^{4}$.

O transcrito acima relata-nos a história de uma funcionária que, com o "tempo de casa", foi deixando as atividades que antes realizava na farmácia para realizar atividades administrativas longe do público. 0 "lá fora”, ao concretizar para os funcionários o contato imediato com o público dito estressado e "valente", torna-se um lugar menos valorizado e mais desgastante. Notou-se um movimento semelhante em vários setores, exemplificado pela fala acima, de migrar com o passar do tempo e com "tempo de casa", de "lá de fora" para "aqui dentro". Configura-se, assim, uma trajetória que valoriza transferir-se de atividades de interface e, desta forma, manter distância do atendimento aos pacientes.

Essas estratégias de distanciamento adotadas podem ser entendidas como uma alternativa da qual os funcionários lançam mão para burlarem o enfrentamento direto de situações árduas no trato cotidiano com os pacientes, familiares e outros usuários. Estratégias que demarcam os agenciamentos, resistências e fugas destes trabalhadores no exercício de suas atribuições. Salientando que o lidar com o público não faz parte apenas do trabalho de médicos, enfermeiros, técnicos de enfermagem e agentes comunitários de saúde, o relacionamento com o público é uma tarefa que direta ou

\footnotetext{
${ }^{4}$ Por se tratar de um centro de saúde relativamente pequeno, optei por omitir ao longo do texto informações que pudessem identificar os/as entrevistados/as. Sendo assim, não foram especificados os cargos e/ou atividades exercidas pelos trabalhadores que participaram da pesquisa, a fim de que se mantivesse o compromisso ético com a equipe de saúde.
} 
indiretamente recai também sobre os funcionários que exercem as tarefas técnico-administrativas e também da limpeza e segurança.

Algumas vezes os setores técnico-administrativos e de segurança tem que lidar diretamente com importantes impactos de humor advindos dos pacientes e seus familiares, recebendo por vezes a primeira descarga emocional. As autoras Bianchessi e Tittoni (2009) demonstram, em sua pesquisa com os funcionários administrativo-operacional, que esses funcionários acabam ocupando uma posição dentro da organização em que, literalmente, ficam expostos aos primeiros impactos e descargas de pacientes e usuários - a chamada linha de frente, como colocado pelas autoras. Considerada como desgastante, a relação com os pacientes foi constantemente descrita pela maioria dos funcionários do CS de Ceilândia como provocadora de desentendimentos, desacatos e, no seu limite, de brigas. Perceber isto foi de certa forma paradoxal, sobretudo porque, institucionalmente, um centro de saúde tem como missão atender as pessoas e oferecer-lhes solução para que tenham condições de restabelecer a saúde.

Na leitura de alguns trechos de entrevistas, é possível traçarmos a figura de um paciente que já chega "armado" ao centro. Um paciente "valente", que chega com o intuito de agredir o funcionário caso suas demandas não sejam atendidas da forma adequada. 0 paciente é, portanto, percebido por alguns membros da equipe como um potencial provocador de desentendimentos e atritos. Seguem, abaixo, as falas que expressam essa ideia que se constrói dos pacientes:

0 paciente vem aqui e às vezes ele já vem armado. Ele já foi passar por um exame no Centro Radiológico, por exemplo, mas não conseguiu marcar um exame lá no hospital, no Hospital de Base, então ele já volta triste. Às vezes desiste do tratamento ou às vezes volta armado. Armado no sentido de que vem para te agredir (Homem, trabalha no Núcleo de Enfermagem).

De certa forma a gente lida com o estresse do público também, seus problemas, aquelas demandas não resolvidas. Tem também o problema político, que de qualquer forma a gente está representando o governo. Então com a saúde que eles vêem na televisão que não está [boa], que está tendo problemas nos outros lugares, ficam irados com aquilo. Aí eles já chegam armados (Mulher, 50 anos, trabalha no Núcleo de Enfermagem).

Por vezes, a idade do paciente, e não sua valentia, é o que se apresenta como motivo de dificuldade na hora do atendimento:

Essa parte de dificuldade de lidar com os pacientes a gente observa principalmente com os pacientes idosos, eles são sexagenários e eles têm dificuldades de compreender e na maioria desses casos eles não são acompanhados de familiares. Eles não conseguem entender corretamente. Então seria muito importante o acompanhamento do familiar. Algumas vezes a gente tem contatado a assistente social, no sentido de ela cobrar [a presença] 
da família e ela me parece ter feito esse trabalho, mas os pacientes insistem em vir sozinhos pras consultas (Homem, 54 anos, Clínica Médica).

Quando falamos da realidade do Centro de Saúde pesquisado e temos em mente a interação com os pacientes, podemos perceber a presença de dois grandes grupos: o grupo composto pelos que trabalham no centro e o grupo integrado pelos usuários do sistema, intitulados pelo primeiro grupo como "o público". Não será demasiado ressaltar que todas as análises aqui desenvolvidas dizem respeito unicamente ao ponto de vista dos funcionários, uma vez que os pacientes não fizeram parte do escopo da pesquisa. Portanto, ao descrever a relação entre os dois grupos, o faço sempre em termos do grupo dos funcionários.

A relação entre estes dois grupos é marcada, como já mencionei, por desentendimentos, afrontas, desacatos e um forte sentimento de antagonismo: afinal, o paciente é entendido como fonte de estresse. A relação de antagonismo que se estabelece chega a ser tão forte que em determinadas situações os pacientes passam a ser percebidos como componentes alheios, tanto para o grupo de funcionários como para as atividades por eles desenvolvidas.

Quando o assunto é o atendimento ao paciente, haveria, de forma geral, uma coesão entre os funcionários baseada na caricaturização de um "paciente valente" que chega até ao atendimento "armado". Ainda que outros fatores, como a presença de pacientes sexagenários desacompanhados de familiares, como visto anteriormente, contribuam para os desentendimentos e estresses na hora do atendimento, os funcionários centram o desenvolvimento dos conflitos a partir de um paciente caracterizado como violento.

Há, em boa parte das entrevistas, um consenso estabelecido quando o assunto é o contato com os pacientes. Nesta relação entre os dois grupos se estabeleceria uma espécie de "círculo vicioso", descrito por Schutz (1979) ao falar das perspectivas internas e externas na relação entre dois grupos: estabelece-se um círculo vicioso, por que o grupo externo, através da reação alterada do grupo interno, fortifica sua interpretação dos traços do grupo interno como sendo altamente detestáveis (ScHUTZ, 1979, p. 86).

Para exemplificar nosso caso usando as ideias desenvolvidas por Schutz (1979) sobre as visões de grupo, bastaria substituir as palavras "externo" e "interno" por "funcionários" e "pacientes", respectivamente. E a expressão "altamente detestáveis" por "altamente desgastante". Com isso quero dizer que haveria uma série de antecipações, por parte dos funcionários, de condutas e valores onde o paciente é sempre visto e apresentado como possível fonte de problema e em geral já chega "armado". A 
ideia do "paciente armado" funcionaria como uma linguagem comum aos funcionários e permitiria, assim, certo nível de coesão dentro do grupo.

Ao se estabelecer esta linguagem comum, é como se a figura do paciente fosse assumindo conotações negativas, sendo gradualmente percebida e encarada como um fator externo às atividades desenvolvidas pelos funcionários. Por ser uma relação marcada por conflitos e desacatos, esquece-se por vezes que o paciente é a razão de ser da própria existência do funcionário e de todo o sistema de saúde.

Não é cabível imaginar um serviço de saúde sem pacientes. A razão de ser dos hospitais e centros de saúde, bem como dos funcionários que ali se encontrem, estressados ou não, é a existência de pacientes. Interessante, porém, que nenhum dos funcionários do CS da Ceilândia entrevistados tenham mencionado que, em muitos casos, os pacientes têm razão de reclamar e de se chatear, porque seu direito de ter acesso e serviços de saúde de qualidade não está sendo respeitado.

Ainda que a equipe de funcionários tenha consciência do direito à reclamação que cabe ao público que é atendido, não se sente responsável pelas adversidades que esse público enfrenta (longo itinerário terapêutico, esperas em filas e não atendimento, por exemplo) e não acham justo ser "agredida” por isso. Talvez por isso não tenha ouvido referências ao "direito do paciente" - ouvi muito o "problema do paciente".

Claro que nem todo problema de saúde é solucionável na atenção básica ou mesmo no sistema biomédico, e muitos dos entrevistados têm clareza disso. Vale lembrar, também, que mesmo fazendo concurso para a Secretaria de Estado de Saúde/DF, mesmo fazendo a formação e carreira em profissões da saúde, não significa que o profissional goste de lidar com pacientes.

\section{Conflito}

O conflito, tão mencionado pelos funcionários, é parte integrante do cotidiano do Centro de Saúde, como já deve estar claro a esta altura. Enquanto tipo de interação, o conflito pode ser entendido sociologicamente como modo de construir um tipo de unidade. A proposta desenvolvida por Simmel (1983), e que está sendo adotada neste trabalho, é que o conflito seja entendido para além de seus aspectos considerados negativos. 0 que está em jogo são as contribuições que o conflito pode trazer para manter a unidade das interações.

Para o referido autor, o conflito seria um tipo de interação que mobilizaria duas forças: o antagonismo - recheado, por exemplo, por antipatias, aversões, desacatos, 
irritações e brigas - e a unidade - preenchida, por exemplo, por atrações, lugares comuns de fala e harmonia. Forças que podem ser separadas conceitualmente, como salienta o autor, mas que empiricamente estão integradas atuando nas interações sociais e, quando bem administradas pelos sujeitos, são geradoras de tolerância e respeito.

A relação dos funcionários com os pacientes caminharia neste sentido. Por mais que se trate de uma relação conflituosa e antagônica, pode-se dizer que em algum momento da interação funcionários e pacientes trabalhariam, num jogo complexo e múltiplo de ações, as forças de antagonismo e de unidade para gerarem um mínimo de tolerância e de respeito:

\footnotetext{
Eu estou sempre sorrindo, eles [pacientes] chegam armados e saem desarmados comigo. Porque se eu estou armada também, aí dá guerra. Sou meio brava. Tem dia que eles vêm bravos e não acham os exames que estão procurando, às vezes não veio ou sumiu. Aí eles ficam valentes, mas eu dou um jeitinho. A gente conversa com ele, alguns entendem, outros não, mas acaba tudo amigo (Mulher, trabalha na entrega de exames).

Ás vezes chega paciente que é agressivo... Que ataca o servidor... Ataca mesmo. Ataca, agride, fala mal, entendeu? E aí você tem que ir lá contornar a coisa ou botar um ponto final na conversa... (Homem, trabalha no Núcleo de Enfermagem).
}

Por vezes, são acionadas intervenções mais pontuais e incisivas, mediadas pela segurança terceirizada do Centro de Saúde ou pela Polícia Militar a fim de que o conflito seja gerenciado:

\footnotetext{
Algumas situações estressam mesmo, já tive que chamar a polícia aqui, uma paciente estava realmente alterada, e agressiva, e correndo no corredor, aí teve que chamar a polícia. Então isso é uma coisa que estressa, porque é responsabilidade minha manter a tranquilidade, manter, né? A harmonia. E os médicos não conseguiam atender, porque ela gritava e xingava os outros pacientes (Mulher, 37 anos, trabalha na Diretoria do Centro).
}

Quando o conflito se torna insustentável e exige intervenção, temos no limite do conflito um tipo bem específico de interação. Ao chegar neste limite, o conflito se torna incapaz de contribuir para a unidade. 0 conflito passa a ser a negação da unidade, afastando assim possíveis cooperações com forças unificadoras. A presença da Polícia Militar, acionada para normalizar, torna o conflito não mais como uma forma sociológica regrada, controlada e ritualizada, como propõe Simmel (1983), e rompe a interação que até então fora estabelecida.

A força unificadora do conflito, de que fala o autor, acaba por perder-se quando o conflito atinge seu limite por meio da intervenção da polícia - que volta a estabelecer a tranquilidade e a harmonia da interação. Sendo assim, o conflito deve aqui ser entendido muito mais como oportunidade para as unificações do que o propósito final 
dessas unificações. Mas há que ressaltar que este reestabelecimento da tranquilidade se dá à custa do silenciamento de um dos termos da relação, o paciente. Nem sempre, portanto, a expressão do conflito é feita por meio de sua resolução.

Dizer que o conflito se estabelece na relação com o "paciente-armado" não implica em dizer que toda relação com os pacientes é perpassada por este conflito, mas sim que este é sempre uma antecipação plausível da interação. Em outras palavras, o conflito com o paciente existe, porém, com variações pessoais e de contexto. Há funcionários, por outro lado, que enxergam a relação com o paciente como motivo de alegria e reconhecimento de bom trabalho:

Gosto do meu trabalho e adoro meus pacientes. Já fiz muita caridade para os pacientes e continuo fazendo. Tem muita gente que precisa da gente, né? Você pode ver que eu sou muito querida pela população (Mulher, trabalha na Coleta de Exames).

Entretanto, por mais que tal funcionária veja no atendimento ao paciente uma fonte de prazer e realização, o bom atendimento prestado é concebido em termos de solidariedade e de caridade, e não conforme a lógica institucional de prestação de um dever. As reclamações dos pacientes e suas adversidades seriam, de certa forma, assumidas pelo funcionário no exercício de suas funções, porém, por meio de um viés paternalista e caridoso.

Para além do que venho retratando aqui, vale dizer que o grupo de funcionários não está isento de atritos e sectarismos internos, ocasionados por oportunidades de trabalho desiguais e desvalorização de determinados tipos de serviço - como os de limpeza e dos agentes comunitários de saúde. Da relação com o paciente surgem, então, diferentes modos de agir que irão depender das tipificações e relevâncias (SCHUTZ, 1979) compartilhadas pelos envolvidos na interação.

O sistema de relevâncias e tipificação funcionaria, seguindo a linha de pensamento desenvolvida por Schutz (1979), como um código de interpretação e orientação que guia a experiência e a ação experimentada pelo indivíduo no mundo. Esse sistema funcionaria "tanto como um código de interpretação quanto um código de orientação para cada membro do grupo interno" (SchUTz, 1979, p. 119). Quero demonstrar, com isso, que apesar de ter feito uma divisão em dois grandes grupos, as categorias propostas aqui são meramente analíticas e o nível de adesão a cada um dos dois grupos varia dependendo dos projetos e anseios de cada pessoa envolvida.

Para além dos sentimentos de antagonismo e unidade, a relação dos funcionários do Centro de Saúde com seus pacientes é também perpassada por outros desgastes 
emocionais. Em alguns momentos das entrevistas foram mencionadas modalidades de sofrimento que remetem a algum tipo de comprometimento do desempenho e do bem estar. Muitas das vezes, esses sofrimentos são ocasionados porque os trabalhadores acabam levando os problemas do dia a dia - que podem ser os problemas do paciente - para dentro de casa.

O desgaste emocional, de que falam os funcionários, configura-se como uma espécie de campo comum de significado que se estabelece na relação com seus pacientes e a estrutura fornecida para o atendimento. Funcionaria como uma linguagem comum na interação, que se estabelece entre os grupos que compõem a hierarquia do atendimento básico. Quando indagados sobre as condições estruturais de seu trabalho, os funcionários evocavam outra dimensão da relação com seus pacientes. 0 paciente, que é visto como fonte de conflito, torna-se também uma fonte de preocupação e de sobrecarga emocional. "Sofre-se", como me foi reportado, por não conseguir atendê-los adequadamente. Os trabalhadores do Centro de Saúde têm consciência de que, enquanto trabalhadores da atenção básica, é seu dever prover um trabalho constante e contínuo, prevenindo hoje e investindo amanhã. Quando se fala da estrutura de atendimento, fica claro que um dos interesses que motivam os funcionários é prestar um bom atendimento à população. Entretanto, nem sempre é possível dispor de condições infraestruturais e de recursos para oferecer um bom atendimento.

Os problemas dos outros, as dificuldades que eles enfrentam. Isso tudo vai indo e mexe com a gente. Isso vai ficando na gente, vai acumulando aquilo ali. E a gente sofre junto. É um tipo de doença emocional, eu diria. Por exemplo, a falta de medicamentos. Quando eu trabalhava lá na farmácia, eu vi gente indo embora chorando. Vi gente falando que, se não tinha ali na farmácia, ele não tinha dinheiro para comprar fora, no particular. Eu vi gente chorando de verdade, desesperada. E eu não podia fazer nada por ela. Nada. Isso é o problema que eu te digo (Mulher, 47 anos, trabalha no $\mathrm{RH}$ ).

ENTREVISTADo: Antigamente a gente ia e não conseguia ajudar então ia ficando frustrado. Mas depois você... Tenta resolver as coisas que não se resolvem a curto prazo.

Pesquisadora: Puxa os problemas pra você?

ENTREVISTADo: Isso, agora você falou tudo. Deixar de ser herói.

Pesquisadora: Como assim deixar de ser herói?

ENTREVISTADO: Deixar de levar os problemas pra casa.

(Homem, 29 anos, trabalha no Programa de Agentes Comunitários de Saúde - PACS).

Se você tivesse uma infraestrutura melhor, você passa esse atendimento melhor para a comunidade. Se você não está se sentindo bem onde está atendendo, te colocam em qualquer lugar para atender, você não está se sentindo bem, você acaba que não atende muito bem também, você quer sair logo dali, uma sala abafada, não tem ventilação, você morre de calor. Tanto você quanto o paciente também, eles reclamam. Se melhorar o lugar, melhora o atendimento também (Homem, 28 anos, trabalha na Nutrição). 
Essas demandas não atendidas dos pacientes e a falta de infraestrutura diagnosticada pelos funcionários seriam responsáveis por gerar impotência, desgaste e frustração. É comum encontrar, na literatura produzida na área da Saúde e das Ciências Sociais, referências sobre a carga emocional e os desgastes psicológicos no fator atendimento ao paciente em relação à falta de estrutura, principalmente nas redes hospitalares. Alguns destes trabalhos, como os de Dalmolin, Lunardi e Lunardi Filho (2009), trazem as problemáticas vivenciadas pelos profissionais da enfermagem de dois hospitais do Rio Grande do Sul em seu cotidiano de trabalho.

Os autores demonstram que em relação ao ambiente organizacional destes profissionais, marcado pela insuficiência de recursos, pela sobrecarga de trabalho e por improvisos para suprir a falta de materiais, há fortes tensionamentos entre o desejo dos funcionários de prestar um bom atendimento e a precariedade de recursos disponíveis. Isso vai de encontro com a última seção de trechos de entrevistas apresentadas neste artigo, que demonstram os conflitos e desgastes que surgem no atendimento ao paciente pela falta de estrutura e de insumos da própria instituição e do próprio sistema de saúde pública.

As relações interpessoais acabam sendo afetadas consideravelmente pela infraestrutura que é disponibilizada ao profissional da saúde, não deixando de afetar, assim, o processo de trabalho como um todo e o seu resultado: o atendimento. Algumas vezes, nas entrevistas, não se falou de si, mas dos colegas, como se fosse um tabu falar e demonstrar as emoções. Como se mostrar o que se sente evocasse uma ideia de fragilidade, que não corresponderia ao que é esperado de um trabalhador da saúde.

\section{Considerações finais}

Buscou-se compreender o trabalho de campo realizado em uma instituição de saúde à luz dos limites e possibilidades das idéias articuladas por Simmel e Schutz. Estiveram em foco, principalmente, as percepções que os funcionários de um centro de atenção básica teceram acerca de seus pacientes e de sua interação com eles. 0 cotidiano de trabalho desses funcionários surgiu como consideravelmente amplo e dinâmico, e aqui optou-se por olhar mais atentamente apenas um de seus aspectos. Privilegiei as considerações e os discursos dos funcionários em relação a seus pacientes, por essa interação ter sido mencionada repetidas vezes em grande parte das entrevistas.

Interação que não se estabelece de qualquer modo, mas é pautada por uma forte carga de antagonismo e desgaste. Assim como falamos de uma interação que tem por 
característica ser conflituosa, não falamos de qualquer tipo de paciente que participa desta interação. A relação é conflituosa justamente por fazerem parte dela pacientes que são considerados "valentes" e que chegam "armados" ao Centro de Saúde.

Talvez pelo fato da pesquisa centrar-se somente na perspectiva dos funcionários e por termos mapeado apenas suas angústias, irritações e motivações, não se tenha encontrado nas entrevistas referências claras e diretas aos direitos do paciente de reclamarem atendimento. Sendo assim, cabem aqui outras indagações etnográficas, como por exemplo: o que significa estar "armado"? O "estar armado" não é justificável do ponto de vista do reconhecimento dos direitos do paciente? Ou também, como se dá a articulação entre as concepções de "caridade", bom atendimento e reconhecimento de direitos e deveres dentro da instituição? Qual o sentido dos conflitos para os pacientes: repressão ou resolução? Silenciamento ou construção de consenso?

Não podemos, é claro, esquecer-nos da posição que os funcionários ocupam em seu cotidiano. Afinal, a atenção básica de saúde é a ponta do SUS que recebe, de forma direta e sem intermediação, o cidadão para ser atendido e também para ser ouvido e reconhecido em suas queixas. Embora os problemas dos sistemas de saúde comecem e se acentuem em esferas mais altas do Estado, são os funcionários do Centro de Saúde estudado, bem como dos demais centros de saúde da capital, que recebem os pacientes "insatisfeitos", "irados”, “ameaçador/as", "angustiados”, “chateados”, "reclamões", "briguentos", "valentes" e "agressivos". Nesse sentido, a atenção básica de saúde funcionaria, metaforicamente, como um entrevistado bem colocou, como "fronte de guerra", a linha de frente de todo o Sistema de Saúde Público.

\section{Referências}

BiAnchessi, D. L. C.; TitToni, J. (2009). “Trabalho, saúde e subjetividade sob o olhar dos trabalhadores administrativo-operacionais de um hospital geral, público e universitário". Physis Revista de Saúde Coletiva, Rio de Janeiro, 19 [4], p. 969-988.

Dalmolin, G. L.; LunARdi, V. L.; Filho, W. D. L. (2009). “O sofrimento moral dos profissionais de enfermagem no exercício da profissão". Rev. enferm. UERJ, Rio de Janeiro, 17(1).

DeSlandes, S. F. (2002). Frágeis deuses: profissionais da emergência entre os danos da violência e a recriação da vida. Rio de Janeiro: FIOCRUZ.

Minayo-Gomez, C.; Thedim-CostA, S. M. F. (2003). "Incorporação das ciências sociais na produção de conhecimento sobre trabalho e saúde". Ciência \& Saúde Coletiva, 8(1), p. 125-136. 
SchuTZ, A. (1979). Fenomenologia e relações sociais. Rio de Janeiro: Zahar Editores.

Simmel, G.; Moraes Filho, E. (Org.) (1983). Simmel. Coleção Grandes Cientistas Sociais. São Paulo: Ática.

Recebido em maio/2012

Aprovado em março/2013 